\title{
Optimization of a Wind Turbine using Permanent Magnet Synchronous Generator (PMSG)
}

\author{
Jan Vergauwe ${ }^{(1)}$, André Martinez ${ }^{(2)}$, Alberto Ribas ${ }^{(3)}$ \\ (1) KAHO St Lieven \\ Gebroeders Desmetstraat 19000 GENT - Belgium \\ (2) EIGSI La Rochelle \\ 26, rue de Vaux de Foletier - 17041 LA ROCHELLE Cedex 1 - France \\ Phone/Fax number: 0033546458045 / 0033546458010 \\ (3) UCO - Departamento Ingenieria Electrica \\ Avda. Menéndez Pidal, s/n. Edificio Servicios Múltiples, planta 514004 CÓRDOBA - Spain \\ email: vergauwe_jan@kaho.com, andre.martinez@eigsi.fr, a.ribas@uco.es
}

\begin{abstract}
This paper proposes strategies for a Wind Turbine with a Voltage Source Converter (VSC) in the case of a 200-300kW Permanent Magnet Synchronous Generator (PMSG). This control allows the synchronous generator to operate at an optimal speed. To show its effectiveness, a mathematical model of a variable speed wind energy conversion system is developed. The mathematical model is used to calculate the response of the wind energy conversion and to determine the maximum power operating point. This paper also provides the theoretical background of this method. Simulation of the system using Matlab / Simulink / SimPower System was performed to illustrate the advantages of this control strategy.
\end{abstract}

Keywords: Wind Turbine, Modelling, PMSG, VSC, Control.

\section{INTRODUCTION}

The realization of a wind turbine as a source of clean, non-polluting and renewable energy may depend on the optimum design of the system and the control strategies of the different possible parameters that can operate efficiently under extreme variations in wind conditions. The general goal of this paper is to optimize the electromechanical energy conversion of the wind turbines, developing suitable strategies of control [1].

Optimum wind energy extraction is achieved by running the Wind Turbine Generator (WTG) in variable speed because of the higher energy gain and the reduced stresses. Using the Permanent Magnet Synchronous Generator (PMSG) the design can be even more simplified. However, the recent advancements in power electronics and control strategies have made it possible to regulate the voltage of the PMSG in many different ways. In the proposed system a VSI converter is preferable $[2,3]$.

Opportune wind turbine architecture is designed using mathematical model of the system. Once the model is made and tested sufficiently, the controller for an optimal command strategy is developed so the wind turbine can perform always in the maximum power point.
The simulation of the curves will show the effectiveness of the controllers developed as well as their advantages and their shortcomings.

\section{WIND ENERGY CONVERSION}

The kinetic energy of the wind (air mass $\mathrm{m}$, wind speed v) is given by the following equation:

$$
E_{c}=\frac{1}{2} m v^{2}
$$

With: $m=\rho v S \Delta t$

(With S: Covered surface of the turbine and $p$ : the air density)

The wind power, $P_{w}$ has the following expression:

$$
P_{w}=\frac{d}{d t} E_{c} \Rightarrow P_{w}=\frac{1}{2} \rho S v^{3}
$$

The mechanical power that the turbine extracts from the wind, $\mathrm{P}_{\mathrm{m}}$, is inferior to $\mathrm{P}_{\mathrm{w}}$. This is due to the fact that the wind speed after the turbine isn't zero (the air needs to be carried of after the turbine). So, the power coefficient of the turbine $\mathrm{C}_{\mathrm{p}}$ can be defined by:

$$
C_{p}=\frac{P_{m}}{P_{w}} ; \quad C_{p}<1
$$

The recuperated power is given by: 


$$
P_{m}=\frac{1}{2} \rho \pi R^{2} v^{3} C_{p}
$$

With R: radius of the rotor.

$\mathrm{C}_{\mathrm{p}}$ depends of the tip speed ratio $\lambda$ of the wind turbine and $\beta$, angle of the blades.

$$
C_{p}=C_{p}(\lambda, \beta) \quad \text { With: } \lambda=\frac{R \omega}{v}
$$

$\omega$ is the rotation speed of the rotor.

A maximum for this function can be found and this maximum is known as the limit of Betz:

$$
C_{P_{\max }}=\frac{16}{27}=0,593
$$

The wind turbine torque on the shaft can be calculated from the power:

$$
T_{m}=\frac{P_{m}}{\omega}=\frac{1}{2} \rho \pi R^{2} \frac{v^{3}}{\omega} C_{p}
$$

By introducing: $\lambda=\frac{R \omega}{v}$ :

$$
T_{m}=\frac{1}{2} \rho \pi R^{3} v^{2} \frac{C_{p}}{\lambda}
$$

Often the torque coefficient $\mathrm{C}_{\mathrm{T}}$ is used:

This gives:

$$
C_{T}=\frac{C_{p}}{\lambda}
$$

$$
T_{m}=\frac{1}{2} \rho \pi R^{3} v^{2} C_{T}
$$

\section{MODELING OF THE SYSTEM}

A wind turbine using Permanent Magnet Synchronous Generator is represented figure 1[4]:

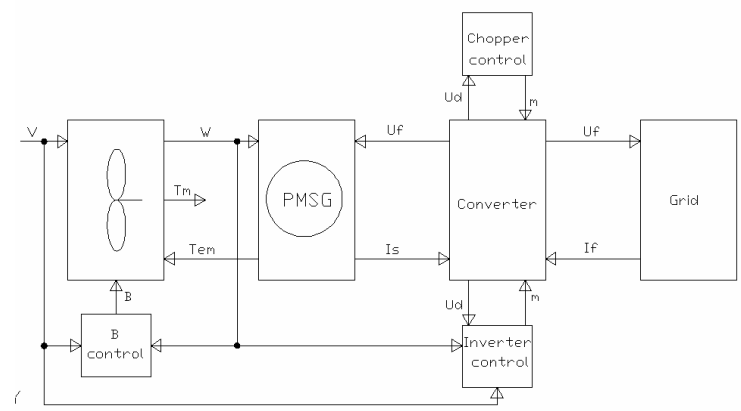

Fig. 1. Wind Turbine using PMSG

The generator is based on the park transformation and the rectifier consists of 6 rectifiers which are placed in bridge layout.

The inverter consists of a MOS inverter and a current controller which generates the control signals for the mosfets. The current controller measures the output currents and compares it with a reference current and changes the control signals of the mosfets in accordance to the difference between the real and the reference currents [5].

Three controlled voltage source blocks are needed because the power system block set contains no sinusoidal voltage sources.

\section{A. Wind Turbine}

The Wind Turbine model is shown in the following scheme:

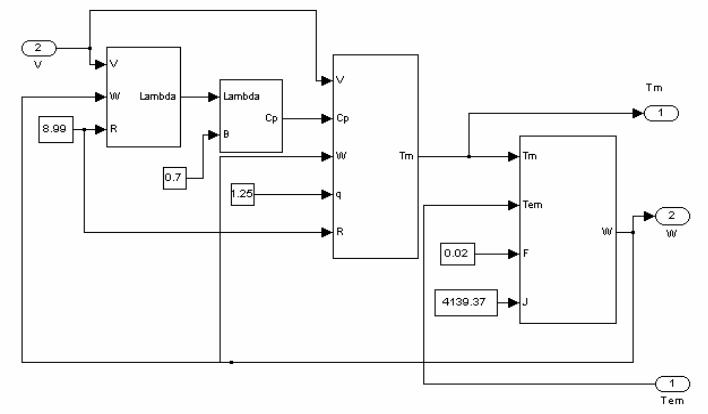

Figure 2: Wind Turbine model

$\lambda$ is calculated in the first subsystem using: $\lambda=\frac{R \omega}{v}$.

$\mathbf{C}_{\mathbf{p}}$ value is calculated in the next subsystem by using the following formula:

$$
C_{p}(\lambda, \beta)=(0,3-0,00167 \beta) \sin \left[\frac{\pi(\lambda+0,1)}{10-0,3 \beta}\right]-0,00184(\lambda-3) \beta
$$

The rotational speed is calculated in the last subsystem by considering the followings:

$$
J \frac{d \omega}{d t}=T_{m}-T_{e m}-F \omega
$$

J: Inertia moment of the turbine, axle and generator F: Axle friction

Tem: Electromagnetical torque

\section{B. Electrical Generator.}

Electrical generator is a permanent magnet synchronous generator (PMSG) with high pole number [6]. The model of the generator is based on the followings equations:

1) $E=k \phi \omega \Rightarrow E=K \omega$ with: E: the no-load voltage of the generator.

2) $T_{e m}=k \phi I_{a} \Rightarrow T_{e m}=K I_{a} \quad$ with: $\mathbf{I}_{\mathbf{a}}$ : the 'active' part of the generator current.

3) $L \frac{d}{d t} I=E-U-R I$

With: $\quad \mathbf{L}, \mathbf{R}$ : the inductance and resistance of the winding and $\mathbf{U}$ : generator Voltage 
The parameters are the followings:

$$
\begin{array}{ll}
\mathbf{S}=125666,6612 \mathrm{VA} & \mathbf{I s}=182,12125 \mathrm{~A} \\
\text { When PF }=0,9549 ; & \boldsymbol{\eta}=94,9493 \\
\mathbf{P m}=126383,238 \mathrm{~W} & \mathbf{T e m}=804,5807 \mathrm{Nm} \\
\mathbf{K}=1,54211 & \mathbf{E}=242,23454 \mathrm{~V} \\
\mathbf{R}=0,0671 \Omega & \mathbf{L}=11,1306 \mathrm{mH} \\
\text { With } & \mathrm{PF}=\text { Power Factor }
\end{array}
$$

\section{The Converter System.}

The model of the rectifier and inverter is simplified because AC current and voltages use effective values [7]. The rectifier and inverter can now be modeled by using simple multiplication factors:

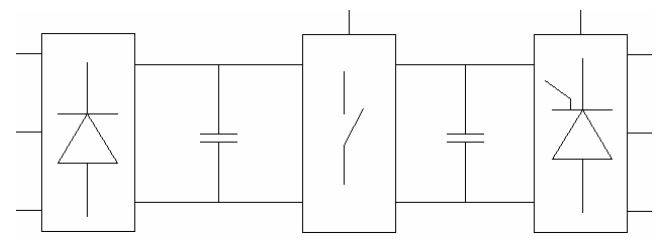

Figure 3: A global overview of the converter

A diode bridge rectifier is used. With the relations:

$$
V_{d}=-\frac{3}{\pi} \sqrt{2} V_{l} \Rightarrow V_{d}=-\frac{3}{\pi} \sqrt{6} V_{f} \Rightarrow V_{f}=\frac{\pi}{3 \sqrt{6}} V_{d} \quad I_{s}=\sqrt{\frac{2}{3} I_{d}} \Rightarrow I_{d}=\sqrt{\frac{3}{2} I_{s}}
$$

The first capacitor is described by the following equation:

$$
C_{\text {cap }} \frac{d}{d t} U_{d}=I_{d}-I_{\text {chop }}-\frac{U_{d}}{R_{\text {cap }}}
$$

The chopper is modeled by two multiplication blocks which are described by the following equations:

$$
U_{d}{ }^{\prime}=m \cdot U_{d} \quad I_{\text {chop }}=m \cdot I_{\text {chop }}{ }^{\prime}
$$

The second capacitor is the same model as the model of the first capacitor and it is based on the same equation. Has a layout which is slightly different from the first capacitor layout.

The inverter is modeled in the same way as the chopper. Two multiplication blocks which give the possibility of regulating the $\mathrm{AC}$ voltage and current with a factor $\mathrm{m}$ which lies between 0 and 1.

\section{CONTROL OF WIND TURBINE}

The power production curve of a wind energy conversion system can be divided in four domains:

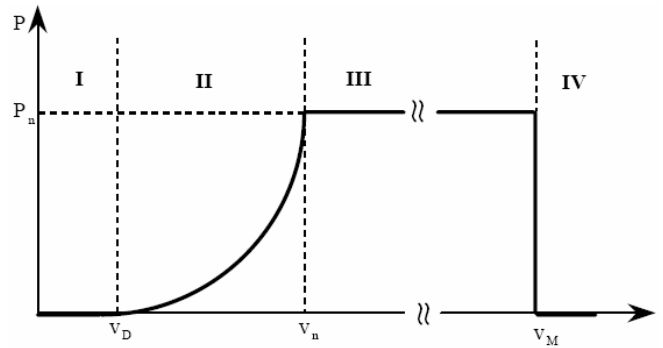

Figure 4: Typical power production curve of a wind turbine

-Zone I: Turbine doesn't turn and the converter is switched off.

-Zone II: Turbine can only work at $\lambda_{\text {opt }}$ in this zone. A real controller is needed in this part.

-Zone III: The power production of the turbine is limited because the generator is already at its maximum power.

-Zone IV: the turbine is stopped from rotating to avoid damages at high wind speeds.

Energy conversion has to be maximized in zone II. In fact, two different controllers are requested. One for zone II, maximization of the power production, and one for zone III, keeps the produced power constant at nominal power [8].

\section{Zone II}

$\lambda$ opt is calculated with previous equations, $(\lambda \mathrm{opt}=4,43507)$. $\omega$ opt is calculated by: $\omega_{o p t}=\frac{\lambda_{\text {opt }} \cdot v}{R}$; $\omega$ opt is compared with real value.

If $\underline{\omega}_{\text {opt }}$ is higher than $\omega$, voltage of the load is set to zero $(\mathrm{m}=0)$. Current will drop and electromagnetic torque of the generator too while the turbine is accelerating.

If $\underline{\omega}_{\text {opt }}$ is lower than $\omega, \mathrm{m}$ is set to; the turbine is slowing down.

The complete controller is given in the following figure:

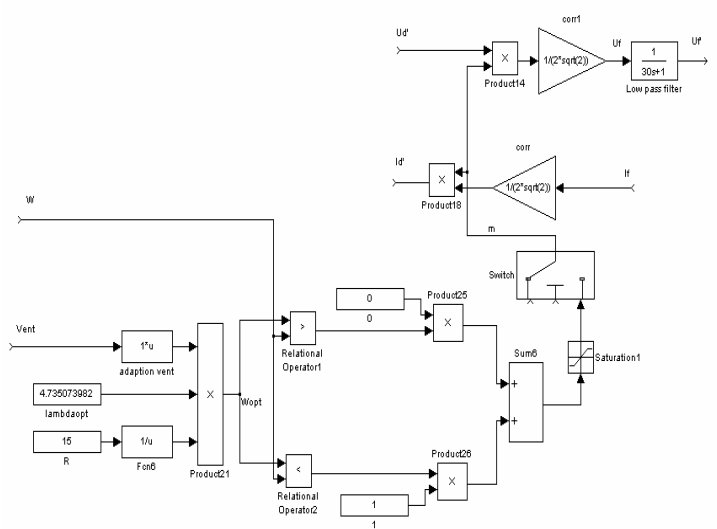

Figure 5: Global controller 


\section{Zone III}

In this zone, the controller doesn't need to maximize the energy production as before; it has to keep the produced power at nominal power.

A stall regulated turbine is used when the nominal wind speed is reached and the power production is automatically reduced. The inverter controller also needs to assure that the electromagnetical couple of the generator remains constant at the nominal couple.

Because the turbine model is the model of a pitch regulated turbine, a control scheme for the attack angle $\beta$ still needs to be developed. The controller adjusts the pitch regulated turbine into a stall regulated turbine.

The current controller is the following:

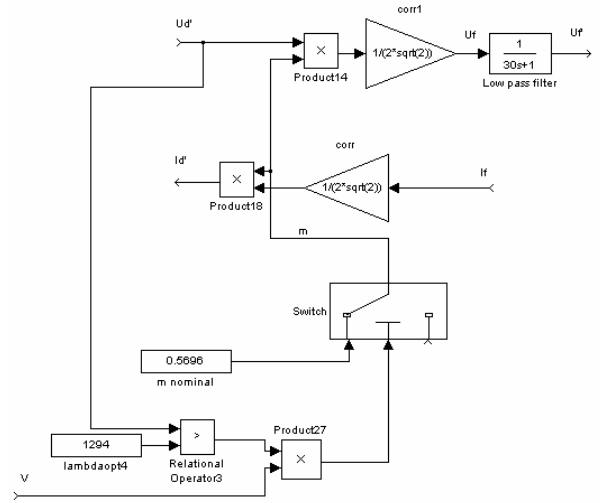

Fig.6: The inverter/current controller for zone III.

The controller for the zone II is linked to this one. The task of this controller is to keep the electromagnetical torque of the generator constant by regulating the current. The only thing that needs to be done is to calculate the $\mathrm{m}_{\text {nominal }}$ by which the nominal current will flow.

\section{CHOICE AN ARCHITECTURE}

\subsection{Choice of a generator-converter combination}

With fixed speed, lower energy gain and higher drive train stresses are obtained. In the case of variable speed, higher energy gain can be reached (turbine can always turn at $\lambda_{\text {opt }}$ in zone II), and drive train stresses is reduced, lower noise emission and power electronics are necessary (increased turbine cost and production of harmonics).
Despite the higher turbine cost and the production of the harmonics, the variable speed technology is more suitable [9].

Three most commonly used architectures of generator-converter combination are: the squirrel cage induction generator, the doubly fed (wound rotor) induction generator, the direct drive synchronous generator. To avoid the gearbox, the synchronous machine is preferable, particularly with permanent magnets. The disadvantages of the converter do not weigh much on the decision because of the very fast changing semi-conductor technology (cheaper and better devices) $[10,11]$.

\subsection{The converter.}

Two different types of converter can be implemented: the Voltage Source Inverter (VSI or VSC) and the Current Source Inverter (CSI). The first has a capacitor in the DC circuit and works with a relative constant DC tension; the second has a winding in the DC circuit and works with a relative constant DC current. The power production of the turbine is controlled by current control of the generator and it is necessary that the generator current go fast. A chopper can be used to change the DC voltage and to keep it constant; it provides also an extra way to control our wind energy conversion system. For theses reasons, a VSI converter is preferable.

\section{RESULTS AND ANALYSIS}

Power production with controllers and power production without controllers in zone II are shown on figure 7 :

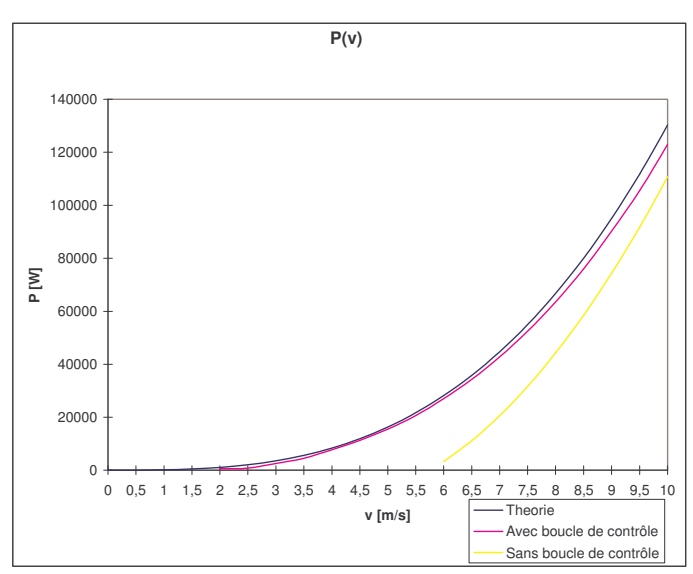

Figure 7: Power production 
Thanks to the controllers there is a bigger power production for all speeds, particularly in the area of the low wind speeds.

The tip speed ratio $\lambda$ obtained is shown on figure 8 . As requested, $\lambda$ tries to stay as close at $\lambda_{\text {opt }}=4,74$ as possible for wind speeds below 10 $\mathrm{m} / \mathrm{s}$.

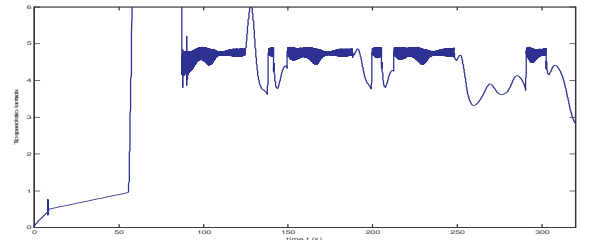

Figure 8: Tip speed ratio $\lambda$

In that case, $\mathrm{Cp}$ is equal to $C \mathrm{p}_{\max }$

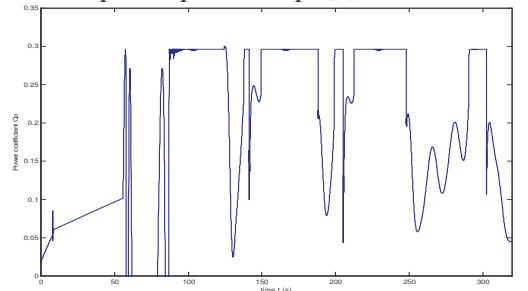

Figure 9: Power coefficient $\mathrm{Cp}$

The generator current and the current of the load are given in the following figures:

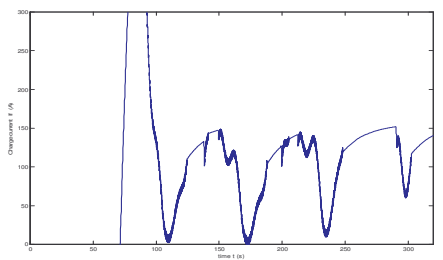

Figure 10: The current of the charge If

The electromagnetical torque produced has the same shape as the generator current.

For wind speeds below $10 \mathrm{~m} / \mathrm{s}$, the power production is maximized by the controllers. For wind speeds above $10 \mathrm{~m} / \mathrm{s}$ the produced power goes to its nominal value:

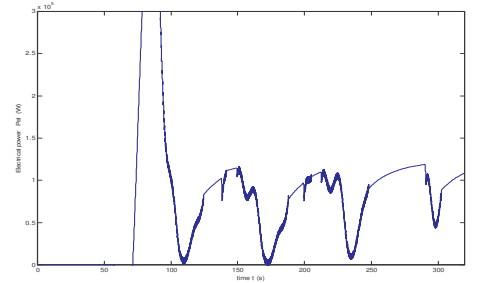

Figure 11: Electrical power Pelec

\section{CONCLUSIONS}

The paper tries to optimize and to maximize the yield of a wind turbine, using permanent magnet synchronous generator (PMSG).
First, variable speed has been chosen because of the higher energy gain and the reduced stresses. A gearbox is not necessary when a synchronous PMSG is used. The chopper has been added to the system to improve the dc voltage. This allows energy gains, even for lower wind speeds.

In the second part, a controller is designed. The pitch wind turbine model is changed to a stall wind turbine model by adding a PI controller for the attack angle. A controller for the chopper voltage has been developed. The developed inverter controller is an all or nothing controller which is a very basic controller.

All results prove that the model developed and controllers demonstrate the effectiveness of adding a controller to obtain the maximum power production.

\section{REFERENCES}

[1] H. STIESDAL; The wind turbine, components and operation; 1999.

[2] H. Slootweg, E. De Vries; Inside wind turbines, Fixed vs Variable speed; Renewable Energy World magazine; 2003.

[3] A. Grauers, Efficiency of three wind energy generator systems, Department of Electric Power Engineering, Chalmers University of Technology, Sweden.

[4] M. Rasilia; Torque- and Speed Control of a Pitch regulated Wind Turbine; Chalmers University of technology; Göteborg, Sweden; 2003.

[5] Thiringer T., Linders J.; Control by variable rotor speed of a fixed-pitch wind turbine operating in speed range; Chalmers university of technology; Göteborg, Sweden; 2003.

[6] Muljadi E., Pierce K., Migliore P., Control strategy for variable-speed stall-regulated wind turbines; National Renewable Energy Laboratory; Golden Colorado.

[7] A. Martinez, F. Lescher, J. Y. Zhao, "An Adaptive Control For Wind Turbine", ICREPQ'05, Zaragoza, March 2005, Spain.

[8] A. Mullane, G. Lightbody, R. Yacamini; Adaptive control of variable speed wind turbines; University College Cork, Ireland; 2001.

[9] M. Malinowski, S. Bernet, Simple control scheme of PWM converter connecting wind turbine with grid; Warsaw University of Technology, Poland; Technical university of Berlin, Germany; 2004.

[10] Ph. DELAURE, A. BOUSCAYROL, A. TOUNZI, X. GUILLAUD, G. LANCIGU. Modelling, control and simulation for an overall wind energy conversion system.

[11] W.Leonhard, Control of Electrical Drives, Springer-Verlag, 2001 